\title{
Declínio do budismo "amarelo" no Brasil
}

Frank Usarski

Introdução

D iferentemente de países ocidentais como a Alemanha - onde o budismo foi introduzido a partir da segunda metade do século XIX mediante oS esforços de um pequeno número de protagonistas ocidentais interessados especialmente na linhaTeravada (cf. U sarski, 1989) -, a história do budismo no Brasil foi iniciada com a chegada dos primeiros japoneses (a maioria de origem rural) no porto de Santos em 1908. Por muitas décadas a partir de então o "budismo deimigração", não exclusivamente (cf. N akamaki, 2002), mas predominantemente na forma do budismo Shin, continuou a ser a única expressão dessa religião no assim chamado "maior país católico do mundo". Além disso, no começo dos anos de 1960, o tradicional templo Soto-Zen Busshin-ji, na cidade de São Paulo, tornou-se o local pioneiro ea fonte primária para um pequeno círculo de vanguardistas não-japoneses interessados na prática do zazen (cf. Rocha, 2006, p. 78). A mesma instituição foi por algum tempo o lar espiritual de Claudia Souza de M uruyama, aliás "M onja C oen" (cf. U sarski, 2006), atualmente uma das figuras simbólicas mais acentuadas do "budismo de conversão" no Brasil. Finalmente, para avaliar a influência da imigração japonesa no budismo brasileiro em geral, não se deve esquecer a alta proporção de templos e centros budistas dos ramos da Terra-Pura e do $\mathrm{N}$ itiren, no espectro das cerca de trezentas entidades budistas no Brasil. 
FIGURA 1

Proporções das Correntes Budistas no Brasil

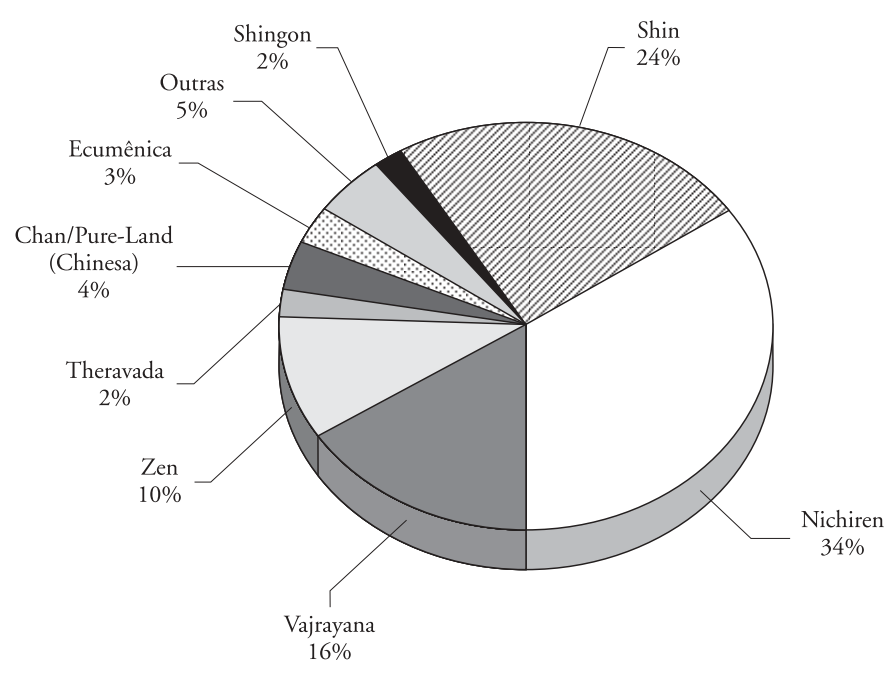

Fonte: Shoji (2004).

Problematização

1. Citado no título do artigo principal "Além do templo - o budismo atrai mais adeptos no Brasil eseus seguidores assumem práticas engajadas", da revista semanal IST OÉ, 1ㅇo out. 2003.

2. A penas para citar quatro exemplos: "0 Brasil dos budas", Istoé, mar. 1997; "O ndazen", Elle, junho de1998; “0 budismo conquista 0 Brasil", Corpo \& M ente, out. 2000; "A ascensão do budismo no Bra sil", Época, junho de 2003.
M anchetes como "O budismo está deixando os templos"1, ladeadas por uma série de artigos e notícias na mídia brasileira sobre um suposto boom da sangha brasi leira², sugerem que, depois de décadas de relativa encapsulação, o budismo japonês tradicional entrou com sucesso em um processo de aculturação e transformou-se em uma religião "da moda". Essa imagem otimista foi severamente desafiada por um artigo publicado na edição de 19 de janeiro de 2001 da revista I stoé, cujo título - "N ão deixe o budismo desaparecer do Brasil" - não combina em nada com as reportagens anteriores acerca do avanço quase inevitável dessa religião. Segundo o artigo, a questão urgente, pelo menos entre representantes das instituições budistas japonesas tradicionais, não era como responder a um dramático aumento de conversões ou a superlotadas sessões, retiros e workshops, mas sim como responder às comunidades declinantes e a dificuldades internas, tais como a falta de staff em certos templos locais.

A reportagem de I stoé não está apenas em sintonia com afirmações semelhantes provenientes das comunidades budistas japonesas tradicionais, mas também com os resultados de pesquisa empírica acerca do assunto. U m exemplo para uma avaliação "êmica" pessimista da situação atual do 
budismo japonês éa afirmação de um funcionário da ComunidadeBudista $N$ ichirenshu de São Paulo, que, em 1995, já tinha enfatizado a existência de muitas pessoas que pensam que o budismo é apenas para os mais vel hos e os monges preenchem sua função somente em termos de ritos funerais (cf. Federação das Seitas Budistas do Brasil, 1995, p. 42). E, em 2004, um ministro líder da Jodo-shin-shu de São Paulo acrescentou:

$N$ a prática, éfácil perceber que os descendentes de japoneses pouco se interessam pelos templos budistas: estão mais preocupados em se integrarem na sociedade brasileira do que em manterem as tradiçoes de seus ancestrais. Assim, não será um exagero dizer que, quando o último imigrante falecer, só resta aos missionários budistas fecharem os templos e regressarem ao Japão, sendo interessante recomendar ainda ao último a partir que desligue a luz antes de seguir para 0 aeroporto (Gonçalves, 2004).

No que diz respeito à pesquisa empírica, os resultados do último censo nacional realizado pelo Instituto Brasileiro de G eografia eEstatística (IBGE) são especialmente relevantes. Entretanto, quando se olha mais de perto 0 "budismo de imigração", os estudos do IBG E devem ser interpretados com cautela. 0 ponto crucial é o item "cor" ou "raça". N o questionário do censo, ele aparece como uma opção de cinco partes diferenciadas a serem correlacionadas com outras categorias, incluindo as que são classificadas sob o título de "religião". Para a identificação dos "budistas imigrantes" a subcategoria na rubrica "cor" que vem espontaneamenteà menteé "amarela". Entretanto, isso é obviamente uma associação ambígua por razões epistemológicas, metodológicas e políticas.

0 principal argumento contra uma interpretação ingênua dos dados do IBGE é que a identificação da cor de uma pessoa no censo deriva da declaração do próprio entrevistado confrontado com um conceito vago e politicamente ambíguo (cf. M aeyama, 1983a, p. 167). Isso vale em especial do ponto de vista de "nipo-brasileiros" que nasceram em famílias etnicamente diversificadas com al to grau de identificação com a cultura ea nacionalidade brasileiras. D ados empíricos comprovam a pertinência das considerações desse tipo. D evido à reprodução em terras brasileiras e a um contínuo fluxo de imigração de japoneses até 1973, complementada pela imigração dechineses e coreanos dos anos de 1950 em diante, o número de brasileiros com antecedente familiar asiático tem constantemente aumentado através das décadas. Como conseqüência dessa dinâmica, é estimado que atual- 
mente mais de 1,5 milhão de brasileiros seja de origem asiática, ea maioria, isto é, cerca de 1,28 milhão, de imigrantes japoneses e seus descendentes (cf. Tsuda, 2000, p. 3). Conforme estimativas, entre 1980 e2000 somente os descendentes de japoneses representavam entre $0,7 \%$ e $0,8 \%$ da população total do Brasil (cf. Beltrão et al., 2006). Entretanto, a porcentagem de indivíduos predispostos a se identificar como "amarelos" não correspondia a esses valores (Figura 2).

FIGURA 2

População do Brasil de Acordo com a C or ou Raça (\%)

\begin{tabular}{l|c|c|c|c|c}
\hline & Branco & Preto & Amarelo & Pardo & Indigena \\
\hline 1940 & 63,47 & 14,64 & 0,59 & 21,21 & - \\
1950 & 61,66 & 10,96 & 0,63 & 26,54 & - \\
1960 & 61,03 & 8,71 & 0,69 & 29,50 & - \\
1980 & 54,23 & 5,92 & 0,56 & 38,85 & - \\
1991 & 51,56 & 5,00 & 0,43 & 42,45 & 0,20 \\
2000 & 53,74 & 6,21 & 0,45 & 38,45 & 0,43 \\
\hline
\end{tabular}

Fonte: IBGE.

Em síntese, deve-se ter em mente que correlacionar as variáveis "budismo" e "amarelo" é heuristicamente limitado em pelo menos dois aspectos. Primeiro: budistas brasileiros que não relutam em identificar a si próprios como "amarelos" podem ser consideradosadeptos com antecedênciafamiliar asiática, sem necessariamente serem descendentes de japoneses. Entretanto, deacordo com as proporções numéricas entre as nacionalidades em questão (japonesa, chinesa ecoreana), o número debudistas de "cor amarela" não perde a sua relevância para o estudo do budismo japonês em particular, desde queelas sejam interpretadas como tendências estatísticas predominantes em um contexto mais amplo. Segundo: a fim de reduzir o risco de distorção, deve-seestar preparado para a possi bili dade dequecerta proporção debudistas brasileiros de origem japonesa apareça nas estatísticas sob outra rubrica quenão a de budistas de "cor amarela". C om isso em mente, a seção seguinte trata da dinâmica em ambos os subcampos do budismo brasileiro.

A evolução estatística do budismo de "cor amarela" no Brasil

Em 2000, somente cerca de 0,14\% da população brasileira optou pela rubrica "budismo" no questionário do IBGE. Esseé um valor bem modes- 
to, mesmo se comparado ao número de adeptos de minorias religiosas tais como os adventistas ( $H^{\prime \prime} 0,73 \%$ ) ou as testemunhas-de-jeová ( $H$ " 0,6\%). U ma comparação com os últimos censos nacionais também nega a difundida idéia de que o budismo é uma religião em constante crescimento. 0 oposto é verdadeiro, especialmente quando se descarta uma relativa distinção entre o budismo étnico e o budismo dos convertidos (cf. Numrich, 1996) e se leva em conta a dinâmica negativa do campo budista em geral entre 1991 (236.408) e 2000 (214.873).

Esse recente declínio do número total de budistas brasileiros não só contradiz os exageros numéricos comuns na mídia brasileira, mas também indica que não se deve contar com a possibilidade de que um número considerável de nipo-brasileiros que se recusaram a continuar declarando-se "amarelos" em 2000 agora apareça sob a rubrica "budista não-amarelo".

A dinâmica negativa no subcampo torna-se ainda mais clara quando se considera a evolução do segmento budista de "cor amarela" durante as últimas três décadas. Comparado aos 149.633 budistas de "cor amarela" registrados em 1970, o número daqueles autodenominados de "cor amarela" caiu para 81.345 em 2000, um declínio de68.288 indivíduos deorigem asiática predispostos a se identificar como adeptos da religião de seusancestrais.

D ados complementares de 1950 - quando se contaram 152.572 budistas, antes das primeiras manifestações do budismo de conversão no Brasil e da imigração chinesa e coreana estatisticamente significativa para o país provam que o declínio do budismo de "cor amarela" foi um processo em andamento por toda a segunda metade do século XX.

Entretanto, a perda entre 1950 e 1970 (2.939 indivíduos a menos) foi relativamente sem importância diante da diminuição muito mais dramática de 59.692 indivíduos ocorrida entre 1970 e 1991 (Figura 3).

D o ponto de vista de al guns representantes de instituições religiosas japonesas tradicionais, a situação nos templos locaiséainda mais preocupante do que a expressa pelo modesto número de budistas de "cor amarela" em nível nacional. Em 2004, o reverendo da A pucarana $\mathrm{N}$ ambei $\mathrm{H}$ onganji, em A pucarana, no estado do Paraná, lamentava-se:

Basta perguntar a qualquer um em meio a essas centenas de participantes que afluem ao templo nosfinais de semana seeles são budistas, para cairmos prostrados por surpresa: menos de $1 \%$ talvez (este número não éoficial... tal vez seja menor) se denomina budista, mesmo que nem saiba exatamente o queéa essência da doutrina budista ${ }^{3}$.
3. Afirmação feita no fórum eletrônico budd hismo@topica.com via mensagem enviada no dia 23 de setembro de 2004. 
FIGURA 3

Evolução N umérica do Budismo no Brasil (1970-2000)

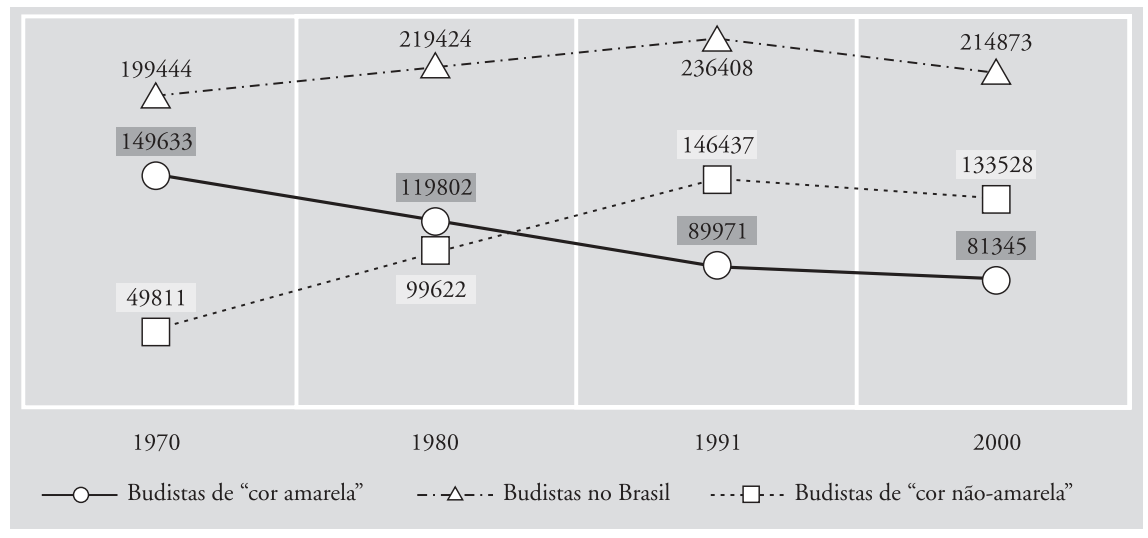

Fonte: IBGE.

O utra indicação de que a situação real é bem diferente da retórica estereotipada de uma explosão do budismo é a situação modesta do templo Busshin-ji na cidade de São Paulo. D e acordo com uma autoridade local, somente cerca de trinta pessoas, a maioria brasilei ros sem ascendência japo-

4. Ver http://www.ipcd igital.com/print_news asp?descrldioma $=$ br\& $\operatorname{codN}$ oticia $=7538$. nesa, freqüentam regularmente as reuniões da instituiçãa ${ }^{4}$.

0 declínio do budismo de "cor amarela" na perspectiva socioistórica e demográfica

Por causa das restrições às atividades religiosas abertas acompanhadas pelo governo japonês, em respeito aos sentimentos da predominante população brasileira católica, etambém devido ao desejo dos imigrantes deprosperar rapidamenteelogo voltar à sua terra natal, areligião japonesa tradicional foi em geral um assunto improvisado com freqüência no interior das famílias, ou - no máximo - entreos vizinhos quepensavam demodo seme Ihante (cf. U sarski, 2002). Somentenos anos de 1950, com uma "ressurreição" geral da religião japonesa (cf. M ori, 1992), éque se favoreceu, antes de tudo, a rápida institucional ização dos templos budistas japoneses tradicionais naquelas áreas urbanas para as quais uma grande parte dos imigrantes, previamente concentrados nas zonas rurais, começou a se mudar em busca de oportunidades econômicas. Entretanto, a consolidação do budismo ea migração urbana representaram duas dinâmicas contraditórias. Enquanto templos recém-fundados ofereciam um espaço para reintegração social e preservação do capital cultural transplantado, a mudança de colônias de demografia "densa" para cidades socioestrutural e ideologicamente heterogê 
neas enfraqueceu a "estrutura de plausibilidade" (Berger, 1985) que havia sido construída e mantida coletivamente de acordo com valores japoneses tradicionais.

Essa discrepância já era evidente no final dos anos de 1950, década na qual uma série de instituições budistas japonesas foi fundada no Brasil. Segundo relevantes estudos, no início do processo de imigração somente uma minoria dos japoneses que se estabeleceu no Brasil era cristã (cf. Fuji e Smyth, 1959, p. 14). D ados de 1958 desenham um quadro completamente diferente. N aquele tempo, somente $44,5 \%$ dos japoneses que viviam no país ainda se sentiam comprometidos com a sua religião tradicional, uma mudança dramática particularmente significativa nas áreas urbanas, onde $50,3 \%$ já se tinham convertido ao catolicismo, enquanto nas áreas rurais o valor correspondente era de 36,5\% (Figura 4).

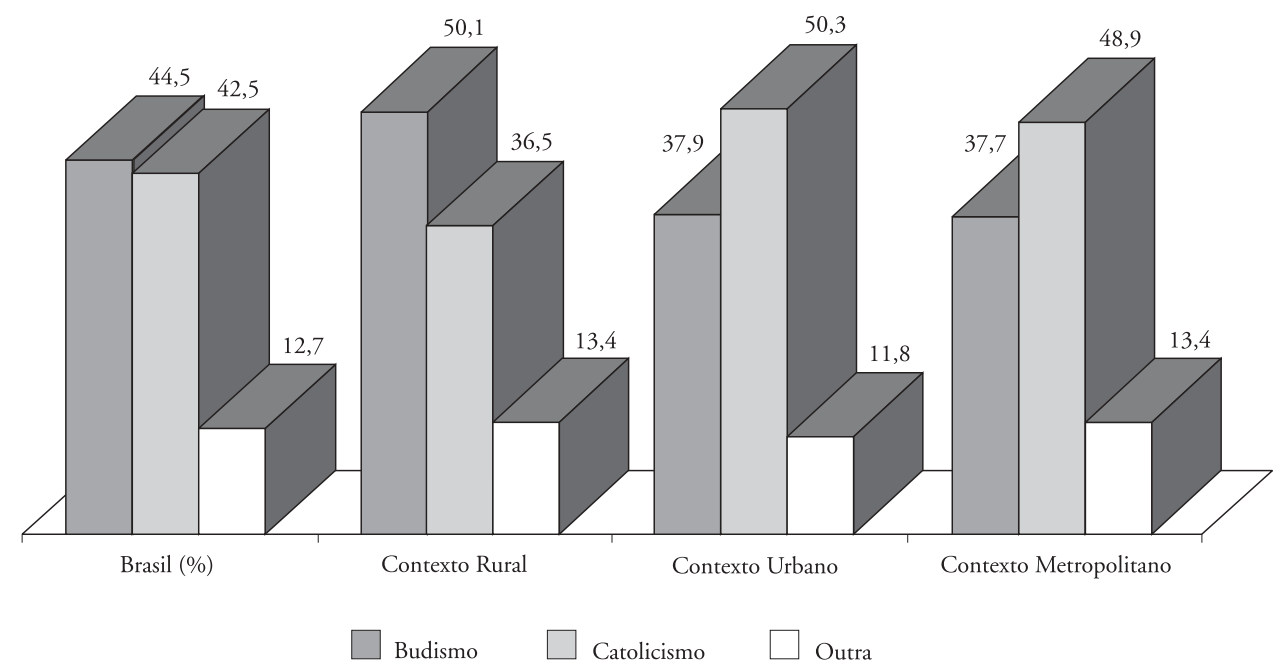

Fonte: Fuji e Smyth (1959).

D ados complementares indicam que, no mesmo ano, a tendência de abandonar a religião japonesa tradicional foi mais forte entre os membros jovens da comunidade de imigrantes japoneses (Figura 5). Enquanto mais de dois terços dos imigrantes nascidos no Japão se declararam budistas, essa porcentagem caiu dramaticamente para $29,9 \%$ entre a geração seguinte nascida no Brasil, e para somente 19\% na terceira geração (cf. M aeyama, 1973, p. 248). 
FIGURA 5

Afiliação Budista ao L ongo de Três Gerações (\%)

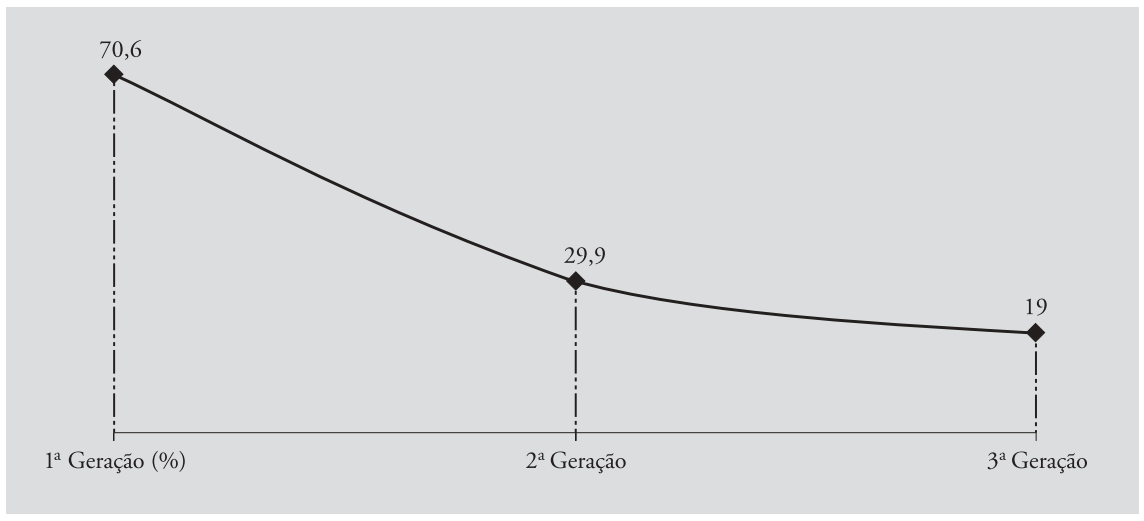

Fonte: M aeyama (1973).

As dificuldades em manter o budismo tradicional no interior das famílias de origem japonesa são espelhadas por relevantes dados derivados dos censos nacionais realizados em 1950 e em 2000. Em 2000, apesar do aumento de cerca de $15 \%$ na população do Brasil ao longo da década anterior, 45,13\% dos budistas de "cor amarela" tinham mais de 60 anos e só 12,19\% tinham menos de 20 anos. 0 significado dessas proporções fica claro quando comparamos esses valores com os gráficos correspondentes fornecidos pelo IBGE em 1950, indicando uma relação inversa naquela época, quando a maioria (51,52\%) dos budistas de "cor amarela" tinha menos de 20 anos de idade, enquanto menos de $5 \%$ tinha mais de 60 anos (Figura 6).

FIGURA 6

O Budismo de "Cor Amarela" Segundo Grupos de I dade em 1950 e2000 (\% )

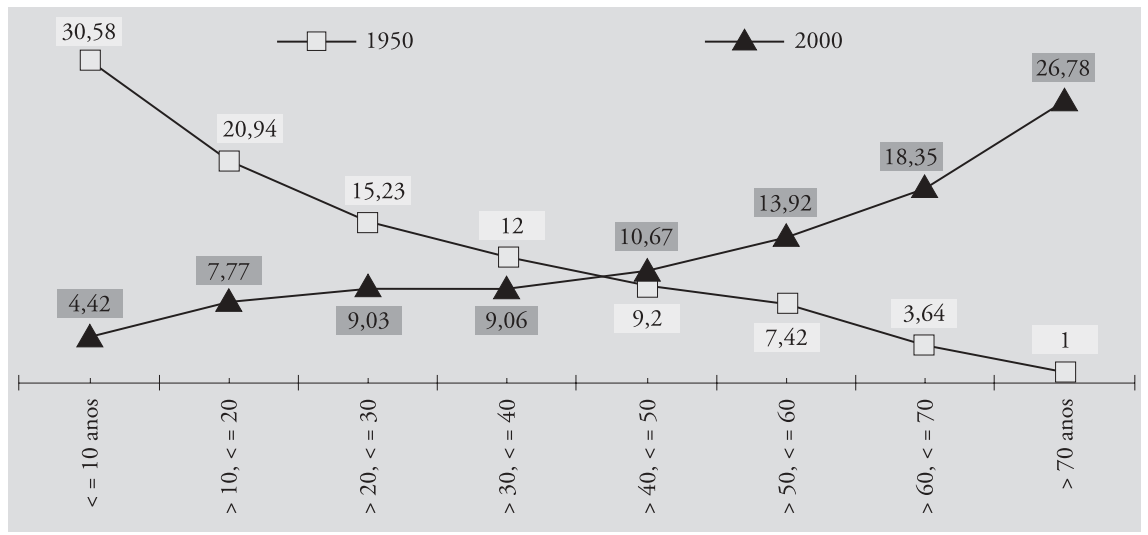

Fonte: IBGE. 
D e acordo com a suposição teórica de que a religião "deve manter um nível de fertilidade suficiente no mínimo para compensar a mortalidade dos membros" (Stark, 1996, p. 140), a fim de sobreviver, essa evolução é um enorme desafio para uma comunidade religiosa incapaz de atrair pessoas sem ascendência japonesa.

Causas do declínio do budismo de "cor amarela" no Brasil

A discussão a seguir sobre as causas possíveis do declínio do budismo de "cor amarela" no Brasil está organizada de acordo com três níveis de reflexão. 0 primeiro consiste na identificação de elementos disfuncionais nas instituições budistas japonesas. 0 segundo corresponde ao problema da manutenção e da transmissão da herança religiosa dentro da comunidade étnica. 0 s aspectos associados primariamente aos indivíduos estão colocados no terceiro nível. É desnecessário dizer que esses três níveis possuem uma íntima relação empírica, e a distinção é feita apenas por propósitos analíticos.

\section{Deficiências no nível das instituiçōes budistas}

Teóricos que favorecem a teoria de escolha racional sugerem que uma exigência religiosa geralmente não se desenvolve no "vácuo", mas como uma resposta positiva a ofertas manifestas fornecidas por instituições religiosas locais (cf. Finke, 1997) quecompetem entre si no propósito de manter seus membros e ganhar novos adeptos. Visto desse ângulo, o budismo em geral e 0 budismo japonês em particular não estão em uma situação confortável no Brasil, simplesmente porque a maioria de suas instituições está concentrada no Sudeste e no Sul do país, mais especificamente em São Paulo, Rio deJaneiro, Paraná eR io Grande do Sul (Figura 7), isto é, naqueles estados que, por décadas, têm sido os preferidos pelos imigrantes japoneses e seus descendentes.

A pesar de a acessibilidade geográfica às instalações de uma religião ser um importantepré-requisito para o sucesso no mercado religioso, os "fornecedores" claramente precisam mais do que sua mera presença física para acompanhar os concorrentes. N essesentido, mesmo que o budismo japonês tradicional conduza uma instituição local, geralmente sofre de duas enormes limitações infra-estruturais: primeiro, a concentração das atividades dos templos nas mãos de apenas uns poucos indivíduos; e, segundo, a falta 
5. Retirado de uma mensagem de Kyoya Imai enviadapor email em 11 de setembro de 2007. deuma estratégia consistente em geral e deuma competência lingüística em particular que sejam capazes de atrair uma audiência mais ampla, não ape nas de fora, mas também de dentro do contexto étnico japonês. Ambos os aspectos são relacionados por um ministro $\mathrm{H}$ onpa $\mathrm{H}$ ongwanji, que, atualmente devolta ao Japão, relembra seustemposno Brasil elamenta: "O s bispos(oslíderes) não abrem a mão parabrasileiros, nem conseguem transmitir mais para os jovens nikkeis. Somente osjaponeses ou nisseis quefalam a línguajaponesa estão nos templos. U m asilo, literalmente" ${ }^{5}$.

FIGURA 7

D istribuição G eográfica das Instituiç̧ões Budistas no Brasil

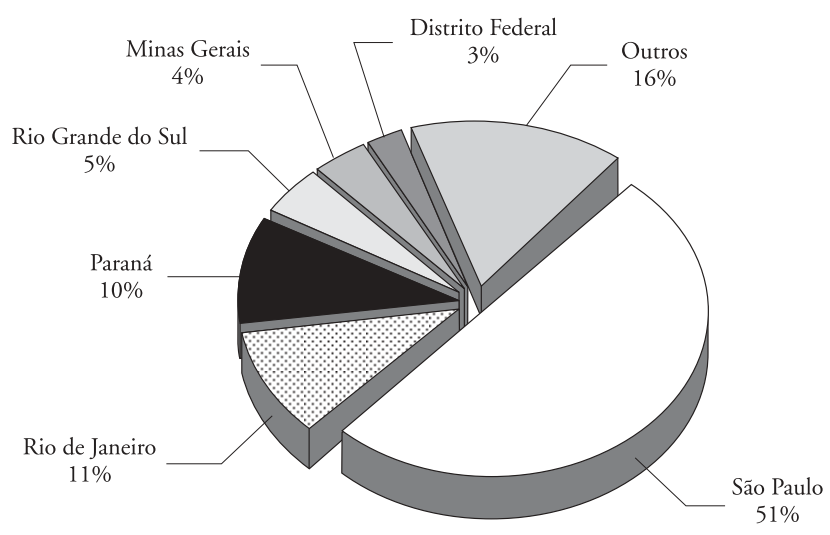

Fonte: Shoji (2004).

A primeira parte dessa crítica enfatiza a falta de espaço oferecido aos brasileiros desejosos de se engajar nos assuntos do templo. Esse aspecto tem si do academicamente discutido em referência à hipótese da coexistência de duas congregações mais ou menos "incompatíveis" nos templos tradicionais, em que um grupo "paralelo" de convertidos está envolvido. Tal constelação tem efeitos negativos para o futuro do budismo étnico no Brasil, como indicado pelas seguintes palavras de uma autoridade $\mathrm{N}$ ichiren-shoshu brasileira: "O s monges provindos do Japão [...] geralmente vêm com a idéia de pregar o budismo como uma filosofia [... . . Acho que aqui isto não funciona. [...] Este é um país de samba, de praia, de carnaval. $\mathrm{N}$ ão é o Japão. A filosofia pode vir de lá, o que é muito louvável, mas nós temos de adaptar este budismo do Japão ao nosso sistema" (Federação das Seitas Budistas do Brasil, 1995, p. 42). 
U m problema mais fundamental surge quando, devido à falta de "força humana" religiosa, uma comunidade é deixada sem uma autoridade religiosa residente, portanto sem uma programação semanal regular. U m exemplo concreto é a filial do $\mathrm{H}$ onpa $\mathrm{H}$ ongwanji, que administra cerca de 45 instituições. Somente a sede central na cidade de São Paulo está bem equipada com um staff religioso, enquanto, por exemplo, mais de vinte comunidades no interior do estado ${ }^{6}$ e três no Paraná 7 não desfrutam da presença permanente de um reverendo local e, em vez demanter atividades regulares do templo, dependem das visitas de uma autoridade religiosa de outra cidade a fim de serem corretamente assistidas.

A segunda deficiênciainfra-estrutural, a falta de uma consistenteestraté gia geral e de competência lingüística em particular, pode ser vista como conseqüência a longo prazo das circunstâncias históricas sob as quais o budismo de imigração foi introduzido no Brasil, numa época em que os imigrantes japoneses ainda estavam convencidos de que a sua moradia no país anfitrião seria temporária. D eacordo com essa postura, atéos anos de 1950 a mai oria das escolas budistas japonesas seabsteve de seorganizar adequadamente, o quefoi contraproducenteem termos não somentedeconsolidação interna eexpansão externa, mastambém deexperiências sobreo quesignifica transplantar de forma sistemática uma religião não-cristã etnicamente diferenciada para uma soci edade de língua portuguesa com predomínio do catolicismo.

Se ocorreram esforços posteriores a fim de compensar essas fal has, eles foram insuficientes. Isso é especialmente verdadeiro em termos de contínuas restrições lingüísticas, como indicado pela seguinte afirmação:

0 ponto de partida para um eficiente trabalho missionário [...] em terras brasileiras não pode ser outro que não um criterioso plano de tradução dos textos sagrados básicos da escola para o português. É necessário realizar essa tarefa com certa urgência, já que a imigração japonesa para o Brasil cessou há muito tempo, os veIhos imigrantes que entendem o japonês estão morrendo e a maior parte de seus descendentes desconhece a língua de seus ancestrais. [...] C aso algo não seja feito nesse sentido desde já, a M issão corre o risco de se ver obrigada a encerrar suas atividades quando o último imigrante japonês no Brasil deixar este mundo (Gonçalves, 1995, p. 9).
6. Em São Bernardo do Campo, Álvares Machado, Adamantina, Andradina, C afelândia, D racena, Flórida Paulista, Guararapes, Itu, Junqueirópolis, Lucélia, M irandópolis, O svaldo Cruz, Pacaembu, Piedade, Pilar do Sul, Pereira Barreto, Pompéia, São José dos Campos, Tremembé, Tupi Paulista, Votuporanga.

7. Em Curitiba, M andaguari e Paranavaí. 
Problemas na manutenção da religiosidade tradicional dentro da comunidade étnica

A direção tomada pela assimilação de um grupo imigrante em seu novo ambiente é uma função de duas lógicas contraditórias: 0 desejo de manter a herança cultural trazida ao país de imigração e a necessidade de integração de acordo com os padrões da sociedade anfitriã.

D urante as primeiras décadas da imigração, o cultivo dos valores japoneses tradicionais em favor da coesão da família e da solidariedade entre seus membros não foi só uma expressão da inten ção dos imigrantes de permanecer no Brasil apenas o tempo necessário, mas também significou um meio de fortalecer a identidade coletiva do grupo como forma de combater os fortes sentimentos antijaponeses externos (cf. Stadniky, 2001). A pós a Segunda Guerra M undial, essa orientação para dentro foi cada vez mais desafiada pelas oportunidades econômicas oferecidas pela sociedade anfitriã em troca da assimilação.

A mobilidade sociodemográfica em resposta a essas oportunidades contribuiu tanto para a crescente flexibilidade dos padrões de comunicação, em prejuízo da línguajaponesa, como para a expansão da malha social além do enclave étnico. Ambas as dinâmicas afetaram a plausível estrutura que antes facilitara a manutenção e a transmissão da herança cultural coletiva, incluindo o budismo tradicional mente praticado como "a religião domiciliar herdada dos antepassados da família" (M aeyama, 1983b, p. 206).

0 impacto negativo da mudança da linguagem tem a ver com o fato de ela ser a ferramenta básica da expressão, preservação etransmissão da cultura própria, portanto um instrumento de importância crítica para manter viva a memória religiosa da família. Visto desse ângulo, e lembrando a insuficiência de material religioso traduzido para o português, podese interpretar o declínio gradual da língua japonesa no Brasil como uma função da falha dos pais na transmissão dela aos filhos.

Ainda que esse processo tenha se tornado mais óbvio durante os anos de 1950, estudos empíricos provam a correspondente tendência já nos anos de 1940, época de medidas políticas rígidas impostas pelo regime nacionalista de $G$ etúlio Vargas, incluindo uma revisão das leis de imigração, um programa de assimilação compulsória para os estrangei ros e a proi bição do uso de línguas estrangeiras em público. Estatísticas relevantes podem ser encontradas num antigo estudo do IBG E sobre as características demográficas de quatro "colônias" de imigração japonesa localizadas no interior de São Paulo. 
Como a Figura 8 indica, já em 1940 um número significativo de imigrantes e seus descendentes havia abandonado sua religião tradicional, uma tendência mais acentuada entre os membros da comunidade abaixo dos 20 anos de idade. Entretanto, essa predisposição foi menos significativa na colônia de Tupã, onde cerca de $98 \%$ ainda preferiam o japonês como 0 principal meio de comunicação. Por outro lado, a mais alta porcentagem de indivíduos que haviam abandonado as religiões japonesas foi encontrada em Presidente Prudente, uma descoberta que não só está positivamente correlacionada com a baixa porcentagem de membros da colônia presos à sua língua original, mas também com a baixa porcentagem de indivíduos com dificuldades de falar português com fluência. D e acordo com estudos posteriores, em 1988 não mais de 45\% dos brasileiros descendentes de imigrantes japoneses usavam o português em casa, enquanto 33\% não tinham conhecimento da língua de seus ancestrais. Essa tendência era mais acentuada nas regiões urbanas, onde a porcentagem de nikkeis que falavam português era de $66,25 \%$, enquanto só $6 \%$ ainda falavam um japonês elaborado (cf. C arvalho, 2003, pp. 39-40). Essa tendência está em agudo contraste com a dominância prolongada da língua japonesa nos templos japoneses tradicionais.

\section{FIGURA 8}

M anutenção da Linguagem e da Religião em 1940 (\%)

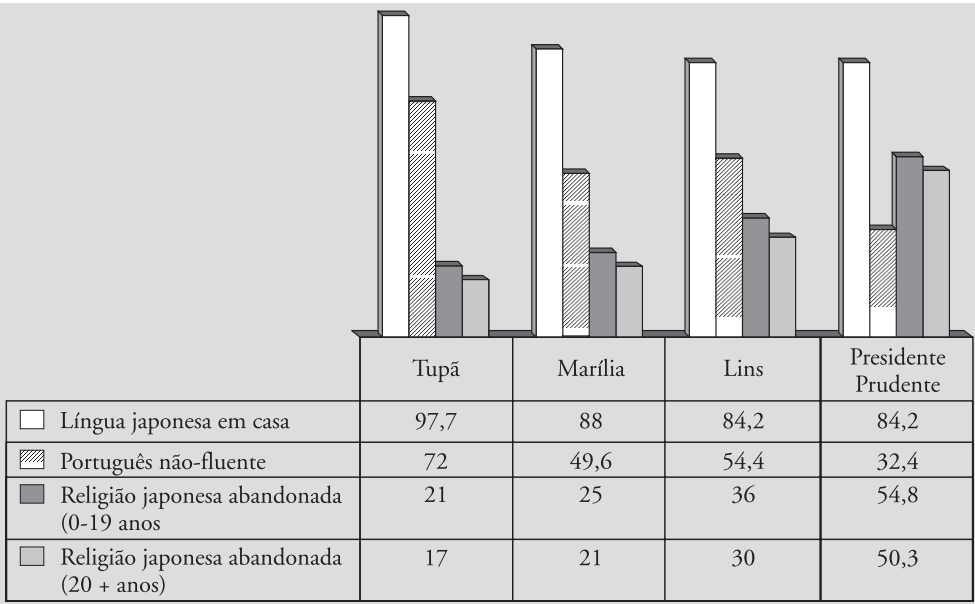

Fonte: IBGE.

Além dos efeitos religiosos colaterais da mudança do japonês para 0 português como língua principal, os esforços em manter o capital cultural 
dentro das colônias foram desafiados por um aumento de casamentos interétnicos, ou seja, por uma prática que "reflete 0 abandono da preferência pelo seu próprio grupo étnico" e representa "um meio de desafiar o sistema familiar tradicional" (Carvalho, 2003, p. 41).

Até os anos de 1940, o casamento fora do grupo era uma rara opção para os japoneses imigrantes. M enos de $2 \%$ dos membros da comunidade nascidos no Japão e menos de $6 \%$ dos nikkeis estavam casados com um cônjuge de origem não-japonesa (cf. Lesser, 1999, p. 104). A pós a Segunda Guerra M undial, a situação mudou gradualmente. Apesar de uma forte hesitação em relação ao casamento interétnico persistir em um nível coletivo, fatores socioeconômicos, inclusive o status da família da noiva em potencial ou a herança do noivo, eram freqüentemente capazes de superar a resistência dos pais, mesmo se seus filhos viam o casamento interétnico como uma oportunidade de suprimir seus traços japoneses (cf. Carvalho, 2003, p. 41). Como resultado, no final dos anos de 1950 e no início dos de 1960, a taxa de casamentos fora do grupo era de $18,36 \%$ para os homens e $7,63 \%$ para as mulheres descendentes de japoneses. D e acordo com dados mais recentes, hoje em dia os casamentos fora do grupo são mais regra do que exceção. Em 1988, não menos de 49,5\% de nipo-brasileiros em todo 0 país estavam casados com um cônjuge não-descendente (cf. Idem, p. 43).

0 papel negativo dessa tendência crescente na manutenção do capital cultural tradicional dentro da comunidade japonesa é óbvio. D iferente de uma família etnicamente homogênea, cuja estrutura de plausi bilidade em geral protege da experiência da contingência religiosa e oferece um contexto para a transmissão mais ou menos coerente de uma visão tradicional do mundo, os casamentos interétnicos, sendo racial e ideologicamente uma "zona mista", requerem do casal respeito mútuo e concessões direcionadas às convicções herdadas e aos valores do cônjuge. A reconstrução da realidade social no interior da recém-formada família pode levar à reconsideração crítica dos assuntos religiosos previamente supostos como auto-evidentes, assim como às "negociações" sobre o caminho correto da socialização dos filhos. Seo diálogo for construtivo, ele enriqueceráo repertório religioso da família. Entretanto, a partir da perspectiva dos indivíduos envolvidos, 0 horizontemais amplo de opções religiosas "aceitáveis" pode resultar em um compromisso reduzido na comunidade religiosa particular na qual cresceram. U ma expressão dessa tendência é a afirmação de um ministro líder Jodo-shin-shu em São Paulo, que em uma entrevista de 1999 al egou que, para muitos jovens nipo-brasileiros, o altar budista doméstico (butsudan) 
havia perdido seu significado. U ma vez que os jovens não mais compreendem por inteiro seu significado religioso, o butsudan écom freqüência associado ao nostálgico interior esteticamente peculiar da casa dos avós, onde supõe-se que seja mantido como parte de uma coleção de parafernálias fora de moda e obsoleta ${ }^{8}$.

\section{Problemas na manutenção da religiosidade japonesa tradicional no nível individual}

$\mathrm{N}$ asúltimas décadas, um alto número desproporcional de nipo-brasileiros tem feito uso, com sucesso, das oportunidades oferecidas por um país "emergente" e suas instituições de educação superior (cf. Adachi, 2004). Em 1985, 13\% dos estudantes e 47\% do corpo docente na Universidade de São Paulo eram descendentes de japoneses (cf. Carvalho, 2003, p. 38). D eacordo com o último censo nacional, cerca de $18 \%$ da população brasileira pertence a uma faixa economicamente privilegiada da sociedade, com rendimentos mensais mais altos do que cinco salários mínimos, isto é, na época, mais do que $\mathrm{R} \$ 1.900,00$. A porcentagem de brasileiros de "cor amarela" era, nesse nível de rendimento, mais do que três vezes mais alta $(55,33 \%)$.

Esses e outros dados similares provam: a) "a amplitude em que a segunda - ou terceira - geração de imigrantes mudou dos padrões de atividade e emprego de seus pais ou avós" (Carvalho, 2003, p. 45); b) a identificação dos descendentes japoneses mais jovens com o Brasil como sua terra natal, merecedor de um "investimento" a longo prazo, e ênfase na educação e no treinamento necessários para uma carreira individual que será remunerada deacordo com o sistema de gratificação inerente a uma sociedade capitalista e tecnológica; e c) seu consentimento aos princípios e valores modernos, tais como individualismo, racionalismo, autonomia e competição.

Em oposição a esse pano de fundo, a questão das possíveis causas do declínio do budismo de "cor amarela" no Brasil, no âmbito individual, pode ser respondida de duas maneiras.

Primei ramente, comparados com a identidade da primeira geração de imigrantes, os avançados processos de "aculturação" individual e a ativa integração dos descendentes mais jovens em sua "sociedade anfitriã" correspondem a uma personalidade na qual três componentes relevantes foram reconfigurados segundo uma nova ordem hierárquica: 0 auto-reconhecimento associado à existência secular como brasileiro, a origem étnica como japonês e o compromisso religioso com o budismo (cf.
8. Citado em minha entrevista com Shaku Riman (Ricardo M ário Gonçalves), 10 demarço de 1999. 
C handler, 1998). Enquanto se pode imaginar que os imigrantes mais veIhos olhavam a si mesmos como budistas japoneses que vieram ao Brasil pelo destino, os descendentes mais jovens, apesar de conscientes de sua herança japonesa, são predominantemente brasileiros. A herança religiosa permanece como uma questão de identidade somente para aqueles que aparecem nos estudos do IBG E como explicitamente "budistas", embora, na maioria desses casos, essa identidade esteja longe de ser um "master status" (cf. H ughes, 1945) internalizado.

Em segundo lugar, a adesão ao budismo em si não é um obstáculo ao sucesso individual. Por outro lado, se é verdade que - como tem sido demonstrado, por exemplo, no caso da umbanda e do pentecostalismo (cf. Fry e H owe, 1975) - a atração de uma religião depende de sua capacidade dese remeter aos conflitos concretos experimentados por sua clientela, podese questionar até que ponto correntes budistas que, como a da Terra Pura, promovem uma atitude "extramundana", baseada na fé, devoção eesperança na força transformadora de um ser transcendente misericordioso, são capazes de satisfazer as necessidades de um indivíduo inclinado à "modernidade" cuja preocupação primária é sua vida profissional "aqui e agora", guiado por princípios tais como racionalismo, autonomia e competição (cf. Bloom, 1998, p. 46).

\section{Conclusão}

U m olhar detal hado aos dados estatísticos referentes ao budismo de "cor amarela" no Brasil revela que a manchete "O budismo está deixando os

9. Ver nota 1. templos" é perfeitamente adequada, mas em um sentido contrário ao sugerido pelos jornalistas responsáveis pela reportagem citada no início deste artigo. Em vez de confirmar a idéia de que o budismo tradicional, que outrora atendia exclusivamente às necessidades religiosas das famílias japonesas imigrantes, começou a atrair uma audiência mais ampla, a frase " 0 budismo está deixando os templos" alude a um possível futuro, quando as instalações das comunidades budistas tradicionais serão esvaziadas de seus praticantes locais

Segundo várias afirmações, as autoridades nos tem plos locais estão conscientes dessa situação precária, mas elas não concordam necessariamenteem sua avaliação. A partir de uma perspectiva mais pessi mista, o atual estado de enfraquecimento do budismo tradicional vai continuar por um bom tempo, já que essa situação é considerada sintomática do duradouro processo de 


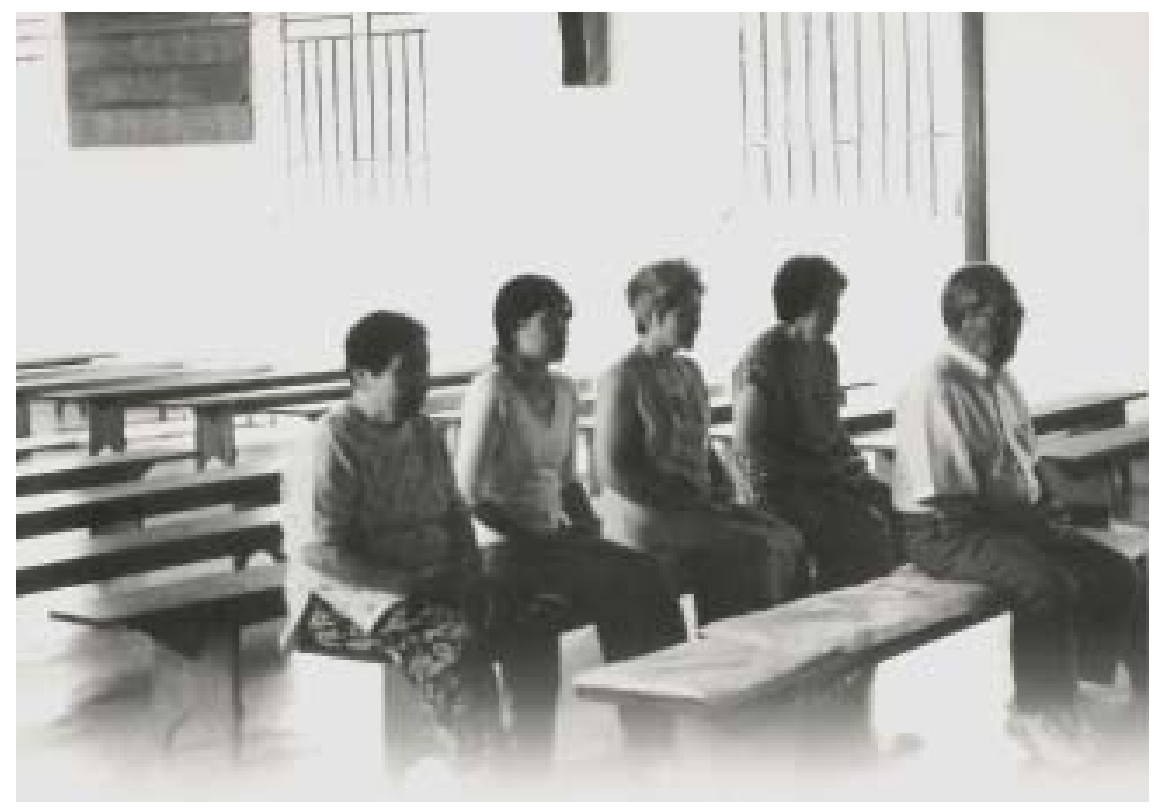

Calendário de 2007 (mês de janeiro) distribuído pela Comunidade Budista Soto Zenshu da América do Sul.

cuidadosa aculturação às novas condições, como no caso das circunstâncias historicamente complexas sob as quais o budismo foi outrora transplantado para o Japão e a C hina. Sob uma luz mais otimista, sinais de mel horamento já são visíveis, como a criação da organização nacional "guarda-chuva” Colegiado Budista Brasileiro eo ativo envolvimento das correntes budistas japonesas tradicionais nessa organização, refletindo esforços em estimular 0 engajamento dos descendentes de japoneses mais jovens nas comunidades budistas (cf. G onçalves, 2005, pp. 206-207).

D eve ser um alívio para as autoridades budistas japonesas tradicionais no Brasil que o declínio estatístico das comunidades budistas de "cor amarela" não esteja restrito ao nosso país, mas seja uma tendência também observável nos Estados U nidos. Ainda que essa disposição negativa seja me nos acentuada nos templos zen norte-americanos de raízes étnicas (cf. A sai e W illiams, 1999), instituições da corrente Shin sofreram os mesmos problemas que suas comunidades "irmãs" no Brasil (cf. Bloom, 1998; Tanaka, 1999). Em ambos os países, as atividades religiosas estavam concentradas nas necessidades da comunidade étnica. Aqui e lá, a língua japonesa continua a representar um papel-chave nos templos, ao custo da alienação de membros e simpatizantes que não a entendem. Existe também o problema comum de envelhecimento dos clérigos e a dificuldade de substituir ministros aposentados por descendentes japoneses mais jovens, desejosos de sa- 
crificar suas ambições profissionais e o sucesso de natureza secular pela manuten ção da tradição religiosa de seus ancestrais. Tanto nos templos brasileiros como nos norte-americanos, a estrutura hierárquica e a valorização da família nuclear como unidade religiosa básica estão em tensão com princípios igualitários e com o individualismo cultivado pela moderna sociedade democrática. Finalmente, em ambos os países, o budismo japonês tradicional é confrontado com sua imagem de uma religião estrangeira, tendo como conseqüência um número insignificante de convertidos.

$M$ as enquanto as autoridades budistas japonesas no Brasil parecem enfrentar a crise com freqüência de modo por demais passivo, os protagonistas do budismo Shin nos Estados U nidos tomaram pelo menos duas iniciativas para extrair virtude da necessidade (cf. Bloom, 1998). A primeira delas consistena "americanização" no âmbito administrativo nacional, promovendo um intercâmbio ecumênico mais efetivo e uma participação mais competente na esfera política. Em segundo lugar, motivadas pelos sinais de uma espéciede "revival étnico", autoridades do templo estão seconcentrando nos membros daúltima geração de descendentesjaponeses, procurando fortalecer o comprometimento com sua comunidade religiosa em vez de dispersar recursos com a propagação de sua féa uma audiência mais ampla. U ma estratégia nesse contexto é o aumento das assim chamadas "escolas dharma", associadas aos templos locais, o que inclui a formulação e a promoção de material de estudo mais em sintonia com o espírito do tempo. Esse empenho pela mudança ideológica é mais bem ilustrado pela ênfase no caráter igualitário do budismo e, vice-versa, pela relativização da importância religiosa dos padrões japoneses tradicionais de comportamento social. $N$ ão se sabe seessas medidas serão adequadas paraa sobrevivência das comunidades budistas japonesas nos Estados U nidos da América. M uito menos se pode prever seelasfuncionarão no Brasil.

Referências Bibliográficas

AdACHI, Nobuko. (2004), "Japonês: a marker of social class or a key term in the discourse of race?". Latin American Perspectives, 31 (3): 48-76, M ay.

Asal, Senryô \& W ILliam S, D uncan Ryûken. (1999), “Japanese American zen temples: cultural identity and economics". In: W ILliams, Duncan Ryûken \& QueEN, Christopher S. (eds.), American buddhism: methods and findings in recent scholarship. Richmond, Curzon, pp. 20-35.

Azevedo, Suami P. de. (2004), Suzano, estrada real. São Paulo, Alto do Tietê. 
Beltrão, Kaizô Iwakami, Sugahara, Sonoe \& Konta, Ryohei. (2006), Trabalhando no Brasil: características da população de origem japonesa segundo os censos entre 1980 e 2000. Trabalho apresentado no XV Encontro Nacional de Estudos Populacionais, Abep, realizado em Caxambu, M G (18 a 22 de setembro).

Berger, Peter L. (1985), 0 dossel sagrado: elementos para uma teoria sociológica da religião. São Paulo, Paulus.

Blo o m , Alfred. (1998), "Shin buddhism in America: a social perspective”. In: PreBiSH, C harles S. \& T An AKA, Kenneth K. (eds.), Thefaces of buddhism in America. Berkeley, University of California Press, pp. 32-47.

Carvalho, D aniela de. (2003), M igrantsand identity in Japan and Brazil: the N ikkijin. Londres/N ova York, Routledge.

Chandler, Stuart. (1998), "C hinese buddhism in America”. In: PreBiSH, Charles S. \& TANAKA, Kenneth K. (eds.), The faces of buddhism in America. Berkeley, University of California Press, pp. 14-30.

Federação das Seitas Budistas do Brasil. (1995), Simpósio e conferência Brasil-Japão de budismo: a contribuição do budismo para a ordem e o progresso do Brasil. São Paulo, Federação das Seitas Budistas do Brasil.

FIN KE, Roger. (1997), "The consequences of religious competition: supply-side explanations for religiouschange". In: Young, LawrenceA. (ed.), Rational choicetheory and religion: summery and assessment. N ova York/Londres, Routledge, pp. 45-61.

FRY, Peter H enry \& H owE, G ary N igel (1975), “D uas respostas à aflição: umbanda e pentecostalismo". Debate \& Crítica, 6: 75-94, jul.

FuJı, Yokio \& SM YTH , T. Lynn (1959), The acculturation of the Japanese immigrants in Brazil. Gainesville, U niversity of Florida Press References.

G on ÇALVEs, Ricardo M ário. (1995), “C onsiderações sobre o trabal ho de tradução de textos budistas". Revista de Instituto Budista de Estudos M issionários, 1: 9-20. - (2004), 0 futuro dos templos budistas no Brasil. Palestra pública por ocasião da celebração do $50^{\circ}$ aniversário do Templo $\mathrm{N}$ ambei $\mathrm{H}$ onganji em Araçatuba (23 de maio).

. (2005), "As flores do dharma desabrocham sob o C ruzeiro do Sul: aspectos dos vários 'budismos' no Brasil". Revista U SP, 67: 198-207, set./out.

H ughes, E. C . (1945), "D ilemmas and contradictions of Status". American Journal of Sociology, 50: 353-359.

IBGE - Instituto Brasileiro de G eografia e Estatística. (1951), Pesquisas sobre os diversos grupos de cor nas populações do Estado de São Paulo e do D istrito Federal. Rio de Janeiro, Serviços G ráficos do Instituto de G eografia e Estatística.

LESSER, Jeffrey. (1999), Immigrants, minorities, and struggle for ethnicity in Brazil. D urham/Londres, D uke University Press. 
M AeYAm A, Takashi. (1973), "Religião, parentesco e as classes médias dos japoneses no Brasil urbano". In: SaIto, H iroshi \& M AEYAM A, Takashi. Assimilação e integração dos japoneses no Brasil. Petrópolis, Vozes, pp. 240-272.

. (1983a), "Culture and value system in Brazil: a preliminary report". Latin American Studies, 6: 153-168.

. (1983b), "Japanese religions in Southern Brazil: change and syncretism". Latin American Studies, 6: 181-238.

M ORI, Koichi. (1992), "Vida religiosa dos japoneses e seus descendentes residentes no Brasil e religiões de origem japonesa". In: Comi ssão de Elaboração da H istória dos 80 Anos da Imigração Japonesa no Brasil: uma epopéia moderna. 80 anos da imigração japonesa no Brasil. São Paulo, H ucitec/Sociedade Brasileira de Cultura Japonesa, pp. 559-601.

N AKAM AKı, H irochika. (2002), "A H onmon - busuryû-shû no Brasil: através de registros do arcebispo N issui I baragui". In: U SARSKI, Frank (org.), 0 budismo no Brasil. São Paulo, Lorosae, pp. 73-105.

N aKam URA, Koryu. (1995), “M ensagem”. In: Simpósio e conferência Brasil-Japão de budismo. A contribuição do budi smo para a ordem e o progresso do Brasil. São Paulo (Federação as Seitas Budistas do Brasil), p. 48.

N U M RICH, Paul D avid. (1996), Old W isdom in the new world: americanization in two immigrant T heravada buddhist temples. Knoxville, T heU niversity of TennesseePress.

Projeto Caixa Populı. (1999), Etnias. São Paulo, Caixa Econômica Federal.

Projeto Caixa Populi, Segunda Etapa. (2000), Japoneses, judeus, chineses, coreanos, gregos, latino-americanos e europeusorientais. São Paulo, Caixa Econômica Federal. Roch A, Cristina. (2006), Zen in Brazil: the quest for cosmopolitan modernity. H onolulu, University of $\mathrm{H}$ awai Press.

SH oJı, Rafael. (2004), Thenativization of East Asian buddhism in Brazil. PhD Thesis, University of $\mathrm{H}$ annover.

SKID M ORE, Thomas E. (1997), "Racial ideas and social policy in Brazil, 1870-1940". In: Graham, Richard (ed.), Theidea of race in Latin America, 1870-1940. Austin, University of Texas, pp. 7-36.

StAd n Iky, H ilda Pívaro. (2001), M igrações para a América: a presença nipo-brasileira no nortenovo de $\mathrm{M}$ aringá. D epartamento de H istória da U niversidade Estadual de M aringá. Paper presented at the $16^{\text {th }} \mathrm{AH}$ E-C ongress in Zaragoza.

Stark, Rodney. (1996), "W hy religious movements succeed or fail: a revised general model". Journal of Contemporary Religion, 11 (2): 133-146.

T An AKA, Kenneth K. (1999), "I ssues of ethnicity in the buddhist churches of America". In: W ILliam S, D uncan Ryûken \& Q ueen, Christopher S. (eds.), American buddhism: methods and findings in recent ccholarship. Richmond, Curzon, pp. 3-19. 
T sud A, Takeyuki. (2000), The benefits of being minority: the ethnic status of the apanese Brazilians in Brazil. Working Paper 21 (M ay 2000), San Diego, University of California, Center for Comparative Immigration Studies.

U SARSKI, Frank. (1989), “D as Bekenntnis zum Buddhismus als Bildungsprivileg. Strukturmomente der 'lebensweltlichen' T heravada-Rezeption in D eutschland im Zeitraum zwischen 1888 und 1924". In: Antes, Peter \& Pahn Ke, Donate (eds.), $D$ ie Religion von 0 berschichten. M arburg, Diagonal, pp. 75-86. . (2002), 0 budismo no Brasil. São Paulo, Lorosae. . (2006), "Abraçando árvores no espírito zen: reflexões sobre o movimento 'Caminhada no Parque'”. Religião \& Cultura, V (9): 99-124.

\section{Resumo}

Declínio do budismo "amarelo" no Brasil

Pesquisas empíricas indicam que o chamado "budismo de cor amarela", sobretudo associado ao budismo de imigração japonesa, está em um declínio constante no que diz respeito a adeptos explícitos. $D$ epois de algumas considerações metodológicas, 0 artigo aborda os dados estatísticos relevantes. N a parte final são discutidas possíveis razões da dinâmica negativa, em conformidade com três níveis de explicação, a saber: motivos relacionados com instituições budistas; constelações dadas na comunidade étnica; fatores no âmbito do indivíduo.

Palavras-chave: Imigração japonesa; Budismo étnico; Preservação de tradição; Aculturação.

\section{Abstract}

The decline of "yellow buddhism" in Brazil

Empirical research shows that 'Yellow Buddhism,' primarily associated with Japanese immigrants in Brazil, is steadily declining in terms of its 'explicit' followers. After some methodological observations, the article examines the relevant statistical data. The final part of the text discusses possible reasons for this negative dynamic at three levels of explanation: namely, internal motives related to Buddhist institutions, configurations within the ethnic community, and factors at individual level.

Keywords: Japanese Immigration; Ethnic Buddhism; Preservation of Tradition; Acculturation.
Texto recebido eaprovado em 8/8/2008

Frank U sarski éprofessor no Programa de Estudos Pós-Graduados em Ciências da Religião da PU C-SP. E-mail: usarski@pucs p.br. 